\title{
Updated Opinion of the Uterus Commission of the Gynecological Oncology Working Group (AGO) and the Gynecological Endoscopy Working Group (AGE) of the German Society of Gynecology and Obstetrics (DGGG) on the Randomized Study Comparing Minimally Invasive with Abdominal Radical Hysterectomy for Early-stage Cervical Cancer (LACC)
}

\author{
Aktualisierte Stellungnahme zur randomisierten Studie der \\ minimalinvasiven versus abdominellen radikalen Hysterektomie bei \\ frühem Zervixkarzinom (LACC) von der Kommission Uterus \\ der Arbeitsgemeinschaft Gynäkologische Onkologie (AGO) und \\ der Arbeitsgemeinschaft Gynäkologische Endoskopie (AGE) der \\ Deutschen Gesellschaft für Gynäkologie und Geburtshilfe (DGGG)
}

(ㄷ) (i) $($ 오 $\ominus$

\section{Authors}

Peter Hillemanns ${ }^{1}$, Sara Brucker ${ }^{2}$, Bernd Holthaus ${ }^{3}$, Rainer Kimmig ${ }^{4}$, Björn Lampe ${ }^{5}$, Ingo Runnebaum ${ }^{6}$, Uwe Ulrich ${ }^{7}$, Markus Wallwiener ${ }^{8}$, Tanja Fehm ${ }^{9}$, Clemens Tempfer $^{10}$, for the AGO Uterus and the AGE of the DGGG

Affiliations

1 Universitätsfrauenklinik, Medizinische Hochschule Hannover, Hannover, Germany

2 Universitätsfrauenklinik Tübingen, Tübingen, Germany

3 Frauenklinik, Krankenhaus St. Elisabeth gGmbH, Damme, Germany

4 Universitätsfrauenklinik Essen, Essen, Germany

5 Frauenklinik, Diakonie Kaiserswerth, Düsseldorf, Germany

6 Universitätsfrauenklinik Jena, Jena, Germany

7 Frauenklinik, Martin-Luther-Krankenhaus, Berlin, Germany

8 Universitätsfrauenklinik Heidelberg, Heidelberg, Germany

9 Universitätsfrauenklinik Düsseldorf, Düsseldorf, Germany

10 Universitätsfrauenklinik der Ruhr-Universität Bochum, Bochum, Germany

Key words

cervical cancer, radical hysterectomy, LACC

Schlüsselwörter

Zervixkarzinom, radikale Hysterektomie, laparoskopische Therapie (LACC)

received $\quad 8.1 .2019$

accepted 9.1.2019
Bibliography

DOI https://doi.org/10.1055/a-0824-7929

Geburtsh Frauenheilk 2019; 79: 145-147 @ Georg Thieme

Verlag KG Stuttgart · New York | ISSN 0016-5751

Correspondence

Prof. Dr. Peter Hillemanns

Universitätsfrauenklinik, Medizinische Hochschule Hannover

Carl-Neuberg-Straße 1, 30625 Hannover, Germany

Hillemanns.Peter@mh-hannover.de

$\Theta$ Deutsche Version unter:

https://doi.org/10.1055/a-0824-7929

\section{ABSTRACT}

In this opinion on the randomized study comparing minimally invasive with abdominal radical hysterectomy for early-stage cervical cancer (LACC), the Uterus Commission of the Gynecological Oncology Working Group (AGO) and the Gynecological Endoscopy Working Group (AGE) of the Germany Society of Gynecology and Obstetrics (DGGG) state that, based on their examination of the published data, patients with FIGO stage IA1 (with LVSI), IA2 or IB1 cervical cancer must be informed about the results of this LACC study prior to making a decision on the route for radical hysterectomy. 


\section{ZUSAMMENFASSUNG}

In dieser Stellungnahme zur randomisierten Studie der minimalinvasiven versus abdominellen radikalen Hysterektomie bei frühem Zervixkarzinom (LACC) stellen die Kommission Uterus der AGO und die AGE der Deutschen Gesellschaft für
Gynäkologie und Geburtshilfe (DGGG) nach Vorlage der publizierten Daten fest, dass Patientinnen mit Zervixkarzinom FIGO IA1 (mit LVSI), IA2, IB1 vor Entscheidung über den geplanten Zugangsweg bei radikaler Hysterektomie über die Ergebnisse der LACC-Studie zu informieren sind.
Ramirez et al. published the results of their randomized study comparing minimally invasive and abdominal radical hysterectomy for early cervical cancer (laparoscopic approach to cervical cancer, LACC) in the New England Journal of Medicine [1]. The primary objective of this international randomized multicenter phase-III study was to investigate the hypothesis that laparoscopic or robot-assisted radical hysterectomy is noninferior to abdominal radical hysterectomy with regard to disease-free survival (DFS) after 4.5 years. Secondary objectives were the rate of recurrence and overall survival (OS).

The study was designed as a noninferiority study and aimed to compare a minimally invasive arm with a standard abdominal arm. The planned number of cases was 740 patients, who would subsequently be followed up for 4.5 years. If the disease-free survival rate in the abdominal arm was $90 \%$, the minimally invasive arm needed to have a power of $87 \%$ to be classed as noninferior to open surgery, based on a $7.2 \%$ noninferiority boundary for differences in disease-free survival. Patients with FIGO stage IA1 (with LVSI), IA2 or IB1 (without lymph node metastasis) cervical cancer histologically classified as primary squamous-cell carcinoma, adenocarcinoma or adenosquamous carcinoma, who showed no signs of metastasis on PET/MRT/CT and underwent type II or III (Piver classification) radical hysterectomy, were included in the study. Participating centers had to submit 10 documented cases of laparoscopic/robot-assisted radical hysterectomy and two non-edited complete video recordings to the study committee. Every surgeon carried out both minimally invasive and open surgery. Adjuvant chemotherapy, radiotherapy and radio-chemotherapy was administered in accordance with standard local practice.

The study started in June 2008 and was stopped prematurely for safety reasons in June 2017 by the Data Safety \& Monitoring Committee after 631 patients (85\%) had been recruited because of the significant inferiority of the laparoscopy arm.

Overall, with 33 centers participating worldwide, fewer than $20 \%$ of patients were recruited in North American centers; the other patients were recruited in centers in South America, India, China, Australia, Italy and Bulgaria. 312 women were randomized to the abdominal arm and 319 women were randomized to the minimally invasive arm. Inclusion characteristics, rates of intraoperative complications and rates of adjuvant therapies were comparable for both study arms; only the rate of tumors with superficial stromal invasion was higher in the minimally invasive arm.

After a median follow-up of $2.5(0.0-6.3)$ years, $59.7 \%$ of the survival data at 4.5 years was available at the time of analysis ( $84 \%$ power): there were 27 recurrences ( $41 \%$ of them in the fornix/pelvis) and 19 deaths in the minimally invasive group and 7 recurrences ( $43 \%$ of them in the fornix) and 3 deaths in the open surgery group.
The rate of disease-free survival after 4.5 years was $86 \%$ in the minimally invasive group and $96.5 \%$ in the abdominal group (difference $-10.6 \%$; $95 \% \mathrm{Cl}$ : -16.4 to $-4.7 ; p=0.87$ for noninferiority); in this respect the data did not provide evidence of non-inferiority. The results were consistent with those obtained from 45 robot-assisted cases (difference $-10.6 \%$; $95 \% \mathrm{Cl}$ : -16.4 to $-4.7)$. The differences in the per-protocol evaluation were also almost identical.

After 3 years, the percentage of disease-free patients (DFS) was significantly higher (97.1\%) in the standard abdominal arm compared to $91.2 \%$ in the laparoscopy arm (hazard ratio [HR] 3.7; $95 \% \mathrm{Cl}: 1.6-8.6)$. The abdominal approach was significantly better (99 vs. 93.8\%) with regard to overall survival (OS: HR 6.0; $95 \% \mathrm{Cl}: 1.8-20.3$ ), disease-specific death (4.4 vs. 0.6\%; HR 6.6; $95 \% \mathrm{Cl}: 1.5-29.0)$ and locoregional recurrence (94.3 vs. $98.3 \%$; HR 4.3; 95\% Cl: 1.4-12.6). The results for robot-assisted and laparoscopic surgery were similar.

Recurrence for tumors with diameters of $2-4 \mathrm{~cm}$ was around 5 times more frequent than for tumors with diameters of less than $2 \mathrm{~cm}$. However, compared with the respective relative risk in the open surgery cohort, the minimally invasive cohort did not have a lower relative risk with regard to the recurrence rate for the subgroup "tumor size less than $2 \mathrm{~cm}$ " compared to the subgroup "tumor size $2-4 \mathrm{~cm}$ ". But the study was not powered for further analysis (e.g., tumor size $<1>2 \mathrm{~cm}$, depth of invasion $<10 \mathrm{~mm}$, no lymphovascular invasion, node-negative).

In addition to this study, a retrospective evaluation of two North American Cancer Registers (NCDB, SEER) was also published in the same issue of the NEJM [2]. Women with FIGO stage IA2 to IB1 cervical cancer treated with open surgery had significantly better survival rates (4-year mortality 9.1 vs. 5.3\%; HR 1.6; $95 \% \mathrm{Cl}: 1.2-2.2 ; \mathrm{p}=0.002)$. The introduction of minimally invasive radical hysterectomy in 2006 coincided with a continuous and statistically significant reduction in survival rates (mortality increased by $0.8 \%$ annually), whereas a continuous improvement in the survival rates of women with FIGO stage $1 \mathrm{~A} 2$ to IB1 cervical cancer had been noted in preceding years.

It was not possible to establish a precise association between minimally invasive surgery vs. open surgery and mortality in the subgroup with tumor diameters of less than $2 \mathrm{~cm}$ and few deaths. However, the $95 \%$ confidence interval shown in the corresponding graph includes the null value (HR 1.5; 95\% Cl: 0.7-3.0), meaning that there was no significance at the alpha level of 0.05 , i.e., there was no difference. The differences between the subgroups with tumors larger than $2 \mathrm{~cm}$ were significant.

In their discussion of the LACC study the authors noted that the very good results of their open surgery arm with its recurrence rate of only $2.4 \%$ after 4.5 years (DFS of $97.6 \%$ instead of $90 \%$ as posited in the study hypothesis) was responsible for the 
lack of noninferiority of the minimally invasive surgery arm (which had a recurrence rate of $13 \%$ and a DFS of $87.1 \%$ ) and attempted to qualify this argument by citing three retrospective studies in which the 5-year DFS in the open surgery arm was between 93.3 and $94.4 \%$ [3-5]. However, in those studies, the DFS in the minimally invasive arm was between 90.5 and $92.8 \%$, i.e. of a similar magnitude. The argument that after 2008 there was a learning curve for the minimally invasive approach was countered by noting that the surgeons in the study had extensive professional experience with this technique. The routine use of uterine manipulators with the potential to disseminate tumor cells in the abdomen during the laparoscopic opening of the vagina and the possibly negative effect of $\mathrm{CO}_{2}$ insufflation were cited as potential reasons for the inferiority of minimally invasive surgery. There is, in fact, a study in which vaginal colpotomy was associated with a lower risk of recurrence than intraabdominal colpotomy [6].

In the summary the authors of the LACC study and US Cancer Registry Evaluation stated that minimally invasive radical hysterectomy was associated with a higher rate of recurrence and poorer overall survival compared to open radical hysterectomy. Previous meta-analyses, which were based on retrospective studies, showed no significant superiority for open surgery.

The results were not interpreted as signaling the end of minimally invasive surgery to treat cervical cancer; instead, it was recommended that studies be done on how to avoid the use of uterine manipulators and the dissemination of cancer cells by ensuring more effective vaginal closure using a standardized approach.

The Uterus Commission of the AGO and the AGE notes that patients with FIGO stage IA1 (with LVSI), IA2, IB1 cervical cancer must be informed about the results of the LACC study prior to making a decision about the planned means of access for radical hysterectomy.

\section{Conflict of Interest}

All authors perform radical hysterectomy by laparoscopic/robotic and/or open surgery.

\section{References}

[1] Ramirez PT, Frumovitz M, Pareja R et al. Minimally Invasive versus Abdominal Radical Hysterectomy for Cervical Cancer. N Engl J Med 2018. doi:10.1056/NEJMoa1806395

[2] Melamed A, Margul DJ, Chen L et al. Survival after Minimally Invasive Radical Hysterectomy for Early-Stage Cervical Cancer. N Engl J Med 2018. doi:10.1056/NEJMoa1804923

[3] Lee E], Kang H, Kim DH. A comparative study of laparoscopic radical hysterectomy with radical abdominal hysterectomy for early-stage cervical cancer: a long-term follow-up study. Eur J Obstet Gynecol Reprod Biol 2011; 156: 83-86

[4] Malzoni M, Tinelli R, Cosentino F et al. Total laparoscopic radical hysterectomy versus abdominal radical hysterectomy with lymphadenectomy in patients with early cervical cancer: our experience. Ann Surg Oncol 2009; 16: 1316-1323

[5] Nam JH, Park JY, Kim DY et al. Laparoscopic versus open radical hysterectomy in early-stage cervical cancer: long-term survival outcomes in a matched cohort study. Ann Oncol 2012; 23: 903-911

[6] Kong TW, Chang S], Piao $X$ et al. Patterns of recurrence and survival after abdominal versus laparoscopic/robotic radical hysterectomy in patients with early cervical cancer. J Obstet Gynaecol Res 2016; 42: 77-86 